\title{
Detection of erbB2 copy number variations in plasma of patients with esophageal carcinoma
}

\author{
Immacolata Andolfo, ${ }^{1,2}$, Giuseppe Petrosino ${ }^{1}$, Loredana Vecchione ${ }^{3}$, Pasqualino De Antonellis ${ }^{1}$, Mario Capasso ${ }^{1}$, \\ Donatella Montanaro ${ }^{1}$, Marica Gemei ${ }^{1}$, Giancarlo Troncone ${ }^{1}$, Achille Iolascon ${ }^{1,2}$, Michele Orditura ${ }^{3}$, \\ Fortunato Ciardiello ${ }^{3}$, Fernando De Vita ${ }^{3}$ and Massimo Zollo ${ }^{1,2^{*}}$
}

\begin{abstract}
Background: Mortality is high in patients with esophageal carcinoma as tumors are rarely detected before the disease has progressed to an advanced stage. Here, we sought to isolate cell-free DNA released into the plasma of patients with esophageal carcinoma, to analyze copy number variations of marker genes in the search for early detection of tumor progression.

Methods: Plasma of 41 patients with esophageal carcinoma was prospectively collected before tumor resection and chemotherapy. Our dataset resulted heterogeneous for clinical data, resembling the characteristics of the tumor. DNA from the plasma was extracted to analyze copy number variations of the erbB2 gene using real-time PCR assays.

Results: The real-time PCR assays for erbB2 gene showed significant $(P=0.001)$ copy number variations in the plasma of patients with esophageal carcinoma, as compared to healthy controls with high sensitivity (80\%) and specificity (95\%). These variations in erbB2 were negatively correlated to the progression free survival of these patients $(P=0.03)$, and revealed a further risk category stratification of patients with low VEGF expression levels.

Conclusion: The copy number variation of erbB2 gene from plasma can be used as prognostic marker for early detection of patients at risk of worse clinical outcome in esophageal cancer.
\end{abstract}

Keywords: esophageal carcinoma cell-free DNA, erbB2 copy number variation, prognostic marker, CTCs

\section{Background}

Esophageal carcinoma (EC) is the eighth most common cancer and the sixth leading cause of cancer-related death worldwide. In European Union, in 2006, were estimated 25.000 cases per years in men and 8.300 in women [1]. In Italy, data from Italian Association for Tumors Registry (AIRTIUM) accounts in 2003, 2.195 cases with 40 new cases per years in Naples (see: http:// www.registri-tumori.it/cms/). The mortality associated with EC is high because tumors are rarely detected before the disease has progressed to an advanced stage. Even when the primary tumor is resectable, the overall 5 -year survival rate is under $10 \%$ [2]. The stage at which EC is detected is the most important factor in

\footnotetext{
* Correspondence: massimo.zollo@unina.it

'CEINGE, Centro di Ingegneria Genetica e Biotecnologia Avanzate, Via

Gaetano Salvatore 486, 80145, Naples, Italy

Full list of author information is available at the end of the article
}

determining prognosis (classified according to the $\mathrm{T}, \mathrm{N}$, $\mathrm{M}$ system). The rate of lymph node metastasis in both squamous cell carcinoma and adenocarcinoma, the two main histological types of EC, is related to the depth of invasion [3-5]. The majority of ECs that present with symptoms have already invaded the muscularis propria (T3) and have already spread to local lymph nodes (N1); this is the reason for the poor prognosis.

New approaches to early detection and monitoring of the course of therapy would benefit the clinical management of patients with EC. Several prognostic factors are currently accepted for clinical use, such as nodal status and tumor stage; however, the disease status and clinicopathological conditions cannot unequivocally identify which patients are at low or high risk for disease recurrence $[2,6]$. Therefore, there remains the need to identify better prognostic markers that can be used with biological fluids $[7,8]$.

\section{Biomed Central}


The human epidermal growth factor receptor (erbB2) oncogene encodes a transmembrane tyrosine kinase receptor that has evolved as a major classifier of invasive breast cancer and a target of therapy for the disease [9]. However, the role of erbB2 in EC is still controversial. Some studies have seen erbB2 over-expression in $20 \%$ to $60 \%$ of ECs, with this wide range indicating that the differences might depend on tumor stage or histology, or on the interpretation of the immunohistochemistry results. Another study underlined the lack of a prognostic impact of erbB2 amplification in primary ECs [10]. An additionally study showed gene-specific quantitative PCR amplification of the erbB2 gene in tumor cells from lymph nodes and bone marrow from 98 patients with EC [11]. In $50 \%$ of $17 q 12.21$ gains, the erbB2 gene was gained in tumor cells from both lymph nodes and bone marrow. Interestingly, only a gain of $\operatorname{erbB2}$, and not of $17 \mathrm{q} 12.21$, was indicative of poor patient survival, suggesting that erbB2 gains are critical for systemic EC. While a gain in erbB2 in a single disseminated cancer cell has been shown to be an important risk factor in multivariate analysis, erbB2 amplification in primary tumors was not associated with poor survival both in a group of patients that were analyzed for disseminated cancer cells, and in a study cohort comprising twice as many patients [11]. Furthermore, erbB2 gene amplification has been demonstrated in the esophageal adenocarcinoma histotype, in 39 patients versus 39 control samples [12].

The formation of new blood vessels (angiogenesis) and lymph vessels (lymphangiogenesis) significantly contributes to malignant growth and metastasis of solid tumors [13-15]. Angiogenesis and lymphangiogenesis are mediated by distinct cytokines and their receptors. The best characterized and most specific cytokines are the vascular endothelial growth factors (VEGF-A, -B, $-C,-D$ and $-E$ ) and their receptors (VEGFR-1, -2 and -3) [16,17]. Clinicopathological and experimental studies on VEGF-C/D expression in esophageal squamous cell specimens and in esophageal adenocarcinoma specimens have been published $[18,19]$. Studies on esophageal squamous carcinoma have resulted in a relatively consistent correlation of growth-factor expression to tumor progression and lymphatic spread. A recent study reported up-regulation of serum VEGF-C in esophageal squamous cell carcinoma, a finding that parallels VEGF-C expression in tissue specimens [20]. They also correlated serum levels of VEGF-C with the presence of lymph node metastasis, and concluded that VEGF-C up-regulation did not arise from platelets or white blood cells.

Many studies have indicated that soluble DNA from tumors can be detected in the serum and plasma of patients with cancers; alterations in both microsatellites and amplification of oncogenes corresponding to the lesions in tumors have been identified in the serum and plasma of patients with several cancers [21-27]. Analysis of DNA from plasma represents a non-invasive method for detection of circulating tumor cells (CTCs) or their DNA released from the primary tumor into the plasma/ serum [21-26]. However, a question that remains debatable is whether this DNA is released from primary dissociating tumor cells or from cells that invade the blood. CTCs have been shown to be a critical link between the primary cancers and metastatic disease, which continues to be the leading cause of death for most malignancies [28]. A sensitive and specific system for quantification of CTCs and their free DNA would thus be a useful diagnostic tool in EC, for monitoring the dissemination of tumor cells into the peripheral serum. As copy-number variations $(\mathrm{CN})$ and overexpression are among the major genomic aberrations in EC pathogenesis, and as the erbB2 gene has been found both in circulating tumor cells from lymph nodes and bone marrow of EC patients, here we studied erbB2 CN variations in the free DNA from plasma of patients with EC [29]. We show that sensitive and fast real-time PCR technology can indeed detect erbB2 $\mathrm{CN}$ variations in the free DNA from plasma of EC patients collected before tumors resection and chemotherapy. We also show that erbB2 CN variations correlates to VEGF levels and that together can be used as predictive markers for worse clinical outcome.

\section{Methods \\ Sample collection}

The present study included 41 patients (men and women; aged 52-74 years) with EC, as diagnosed by the Dipartimento Medico-Chirurgico di Internistica Clinica e Sperimentale "F. Magrassi e A. Lanzara" SUN, Seconda Università degli Studi, Naples, Italy. The ethics committee of the SUN approved this study, and informed written consent was obtained from all of the patients before inclusion in the study. The clinicopathological characteristics of the EC patients are described in Additional file 1: Supplemental Table S1. Thirty-four peripheral EDTA blood samples from 34 healthy volunteers formed the negative control group. The peripheral blood of both cases and controls was centrifuged at $2850 \times g$ for $10 \mathrm{~min}$ at $4^{\circ} \mathrm{C}$, and the supernatant (plasma) was stored at $-80^{\circ} \mathrm{C}$ until analysis. The time lag between blood collection and plasma processing was at most of four hours for both EC patients and healthy controls.

All of the plasma samples from the patients with EC included in the present study were collected before surgical tumor resection and before chemotherapy treatment. 


\section{DNA preparation from plasma}

A total of $500 \mu \mathrm{L}$ of plasma was treated with $1 \mathrm{mg} \mathrm{mL}^{-1}$ proteinase K (GIBCO) and 10\% SDS (Sigma Aldrich) for $1 \mathrm{~h}$ at $65^{\circ} \mathrm{C}$. These samples were then heated to $95^{\circ} \mathrm{C}$ for $10 \mathrm{~min}$, to inactivate the proteinase $\mathrm{K}$. The DNA in the samples was then phenol extracted and ethanol precipitated. After centrifugation at $6000 \times g$ for $15 \mathrm{~min}$ at $4{ }^{\circ} \mathrm{C}$, the DNA pellets were dissolved in $30 \mu \mathrm{l}$ sterile water.

\section{Cloning of the real-time PCR amplification products of erbB2 and $\beta$-actin for copy number analysis}

Following PCR amplification, the real-time PCR amplification products for $\operatorname{erbB} 2$ and $\beta$-actin were cloned separately into the pcr 2.1 vector, using the original TA cloning system (Invitrogen). Briefly, fragments of the erbB2 and $\beta$-actin genes were amplified from genomic DNA of healthy control peripheral blood. The PCR primers and cycling conditions were the same as those used for real-time PCR of the DNA from the EC patients. After the cloning into the pcr 2.1 vector, the erbB2 and $\beta$-actin plasmids were prepared at a concentration of $100 \mathrm{ng} / \mu \mathrm{l}$.

\section{Determination of ErbB2 copy number variations Real-time PCR}

Real-time quantitative PCR (Syber Green method) was performed using standard protocols with an Applied Biosystems ABI PRISM 7900HT Sequence Detection system. Briefly, $100 \mathrm{ng}$ DNA was added to $12.5 \mu \mathrm{l}$ of SYBR-green PCR master mix (Applied Biosystems), with $600 \mathrm{nM}$ of each primer, and water to $25 \mu \mathrm{l}$. The reactions were amplified with a single step of $2 \mathrm{~min}$ at $50^{\circ} \mathrm{C}$, and $5 \mathrm{~min}$ at $95^{\circ} \mathrm{C}$, and then for 40 cycles of $5 \mathrm{~s}$ at $95^{\circ}$ $\mathrm{C}$, and $1 \mathrm{~min}$ at $60^{\circ} \mathrm{C}$. The thermal denaturation protocol was run at the end of the PCR to determine the number of products that were present in the reactions. All of the reactions were run in triplicate and included non-template controls for each gene. The amount of each gene was normalized to $\beta$-actin as the reference gene. The real-time PCR primers for each gene were designed using the Primer Express software, version 2.0 (Applied Biosystems), with a Tm of $60^{\circ} \mathrm{C}$ and a primer length of between $18 \mathrm{nt}$ and $25 \mathrm{nt}$. We used a standard analysis to calculate the amplification of the $\operatorname{erbB2}$ genes by the $2^{\wedge}$-DCt method as described previously [30]. The real-time PCR was performed twice for each sample, and we used the mean value of these two independently data points.

\section{Calibration curves}

For each assay, we prepared a reference calibration curve as described previously, [31] which containing a nine-concentration titration series representing the
erbB2 and $\beta$-actin genes at 10 -fold dilutions from 1.0 $\mathrm{ng} / \mu \mathrm{l}$ to $1.0 \times 10^{-8} \mathrm{ng} / \mu \mathrm{l}$ (see Additional file 2: Supplemental Figure S1). Each calibration curve was produced in triplicate. We tested the reproducibility of the calibration curves for erbB2 and $\beta$-actin genes determination according to the slopes and the correlation coefficients of the experimental fittings of the calibration curves from each experiment. The mean slopes of the calibration curves for the two genes were similar: -3.285 for erbB2 and -3.036 for $\beta$-actin. The mean correlation coefficients of the curve fitting were 0.989 and 0.994 , respectively. We here, showed three representative slopes for $\beta$-actin and erbB2 with the standard errors: slopes $\beta$-actin: $-3.122 ;-2.772 ;-3.215$, standard deviation is 0.234 and standard error is 0.135 ; slopes erbB2: $-3,263 ;-3,232 ;-3,360$, standard deviation is 0,066 and standard error 0.039 . A slope of $-3.3+/-10 \%$ reflects an efficiency of $100 \%+/-10 \%$ of the PCR reaction [32]. For this reason, the slopes for the two genes are similar ( $p$ values $=0,150)$. We calculates these gene $\mathrm{CN}$ of the patients using the $\mathrm{Ct}$ values of the vector and calculating the $\mathrm{CN}$ vector according to the formula [31,33,34]:

$$
\begin{aligned}
\text { Number of copies }= & \left(\text { amount }(\mathrm{ng}) * 6.022 \times 10^{23}\right) / \\
& \left(\text { length }(\mathrm{bp}) * 1.0 \times 10^{9} * 650\right) .
\end{aligned}
$$

This formula takes into account $6.022 \times 10^{23}$ (molecules/mole) that is the Avogadro's number and $660 \mathrm{Da}$ that is the average weight of a single base pair. The non-integer results were treated on the basis of the cutoff $\mathrm{CN}>2$ and $\mathrm{CN} \leq 2$ and they were rounded off, particularly, the values were rounded down if the decimal value was between 0 and 4; while they were rounded up if the decimal value was between 5 and 9 .

The primers for the $\operatorname{erbB} 2$ gene were:

erbB2 F: TATGCAGGGCTGACGTAGTGC

erbB2 R: AATGTGTGCCACGAAACTGCT

The primers for the $\beta$-actin gene were:

$\beta$-actin F: CCTCACCCTGAAGTACCCCA,

$\beta$-actin R: TCGTCCCAGTTGGTGACGAT.

\section{Cell sorting of circulating tumor cells by flow cytometry}

Whole peripheral blood samples from six EC patients were centrifuged at $2850 \times g$ for $10 \mathrm{~min}$ at $4^{\circ} \mathrm{C}$, and the plasma was removed. The resulting cell pellet was suspended by dilution with phosphate-buffered saline (PBS) and then centrifuged at $1700 \times g$ for $30 \mathrm{~min}$ at $4^{\circ} \mathrm{C}$, to separate mononuclear cells. Then, the mononuclear cells were stained at $4^{\circ} \mathrm{C}$ and avoiding light exposure, with: cytokeratins CK8-, CK18-, and CK19-FITC (monoclonal antibody A45-B/B3; Micromet, Munich, Germany) 1:30; CD326-APC (EpCAM, Becton Dickinson) 1:10; and CD45-PerCP (Becton Dickinson) 1:10. The samples were then washed with $2 \mathrm{ml}$ PBS with $2 \%$ fetal 
bovine serum, and centrifuged at $800 \times \mathrm{g}$ for $3 \mathrm{~min}$ at $4^{\circ}$ C. The supernatant was removed and the cell pellets were suspended as before $(2 \mathrm{ml}$ PBS with $2 \%$ fetal bovine serum), and filtered with $30 \mu \mathrm{m}$ filcons (Becton Dickinson) before analysis by flow cytometry. The flow cytometry gating strategies included: a first gate based on physical parameters forward scatter (FSC) versus side scatter (SSC), to eliminate cell debris and dead cells. The leukocyte population was excluded with a second gate in the CD45 versus SSC dot plot. The CTCs were selected by a gate based on cytokeratin CK8, CK18 and CK19/CD326-positive cells. These cells were purified by cell sorting with a BD FACS Aria instrument, and collected in a $2 \mathrm{ml}$ tube.

\section{Immunohistochemistry}

One or two representative tumor blocks from each patient were examined by immunohistochemistry. We analyzed erbB2 for 14 EC tissue samples with an anti-erbB2 antibody (1:500; DakoCytomation). The unmasking was performed in $10 \mathrm{mM}$ citrate buffer, $\mathrm{pH} 6$, for $45 \mathrm{~min}$ at $97^{\circ} \mathrm{C}$. Blocking was performed with BSA 2,5\%, normal goat serum $0.05 \%$, PBS $1 \%$, Tween $0,5 \%$ for $1 \mathrm{~h}$ at room temperature. The signal was revealed according to DAKO kits, for $15 \mathrm{~min}$ (each, for biotin and streptavidin), at room temperature. DAB was from DakoCytomation, and the slides were mounted and examined under a Leica DC500 compound microscope (Nussloch, Germany).

ErbB2 immunohistochemical staining in EC samples was scored according to Kuwabara et al., [35], who adopted the same criteria previously validated for breast cancer; namely: no staining or weak staining in fewer than $10 \%$ of the tumor cells (-); weak staining in part of the membrane in more than $10 \%$ of the tumor cells $(+)$; complete staining in part of the membrane with weak or moderate intensity in more than $10 \%$ of the tumor cells, $(++)$; strong staining in more than $10 \%$ of the tumor cells, $(+++)$.

\section{VEGF ELISA assay}

The levels of the VEGF protein in the plasma used for erbB2 amplifications from 41 EC patients were determined using a commercially available sandwich enzyme immunoassay kit (Endogen VEGF ELISA kit, Cambridge, USA). All sample were assayed in duplicate.

\section{Statistical analysis}

All of the data are presented as medians \pm standard error. Statistical significance was calculated using the Mann-Whitney test. Raw real-time PCR data for erbB2 amplification in the plasma from healthy controls and patients with EC were normalized using the $\beta$-actin amplification values. The $\operatorname{rbB} 2 \mathrm{CN}$ values were divided into two groups, as " $\mathrm{CN} \geq 2$ " and " $\mathrm{CN}<2$ ". Potential associations between clinicopathological variables and erbB2 CN were analyzed by Pearson's Chi-Squared. Kaplan-Meier survival curves were constructed for erbB2 and VEGF low and high level groups, as well as for the clinicophathological variables available in our dataset. Differences in survival between the groups were tested for statistical significance by log-rank tests. Progression free survival time was measured from the date of registration in the study to the date of progression or last follow-up visit. The patients derived all from one clinic and were all of Caucasian origin. $P<0.05$ was considered as statistically significant.

Receiver operating characteristic (ROC) curves and the area under the ROC curves were generated to calculate the specificity and sensitivity of erbB2 $\mathrm{CN}$ variation in the healthy controls and the EC patients.

\section{Results}

Detection of erbB2 copy number variations in DNA from plasma of patients with esophageal carcinoma

Real-time PCR with CN analysis was used for the analysis of DNA from the plasma of 41 patients with EC, before their surgical resection and chemotherapy treatment. Here, we also analyzed the $\mathrm{CN}$ variations for erbB2 in 34 healthy controls. As shown in Figure 1A, the $\operatorname{erbB} 2 \mathrm{CNs}$ were significantly higher in the plasma samples from the $41 \mathrm{EC}$ patients, with respect to the 34 healthy control subjects $(P=0.001)$. In particular, 24 EC patients had $\mathrm{CN} \leq 2$ (58.5\%), while 17 EC patients had $\mathrm{CN}>2(41.4 \%)$ with a median $\mathrm{CN}$ of 2 and a standard deviation of 5.02 . The 34 healthy control subjects showed a median of erbB2 $\mathrm{CN}$ of 1 , with a standard deviation of 0.16 . The representative calibration curves for the erbB2 and $\beta$-actin genes used for the $\mathrm{CN}$ variation analysis are shown in the Additional file 2: Supplemental figure S1 (Figure S1).

We also evaluated the $\mathrm{CN}$ data of erbB2 by real-time PCR using the ROC curves, which provide an analysis of the sensitivity and specificity of the assay. The ROC curves were constructed for the erbB2 CN in plasma, examining the $41 \mathrm{EC}$ patients and 34 healthy controls. As shown in Figure 1B, in this sample set, erbB2 had an area under the curve (AUC) of 0.95, and differed significantly from that of a chance result (AUC: 0.5$)(P=1.39$ $\left.\times 10^{-11}\right)$. For distinguishing patients with EC from healthy controls, erbB2 had an $80 \%$ sensibility, and a 95\% specificity (Figure 1B).

The association of the $\operatorname{erbB} 2 \mathrm{CN}$ variations with the clinicopathological characteristics of the EC patients are summarized in the Additional file 1: Supplemental table $\mathrm{S} 1$. The association of erbB2 $\mathrm{CN}$ and the clinical features of the esophageal carcinoma were also assessed by the Chi-Squared Test. There were no significant statistical direct correlations between erbB2 $\mathrm{CN}$ and these 


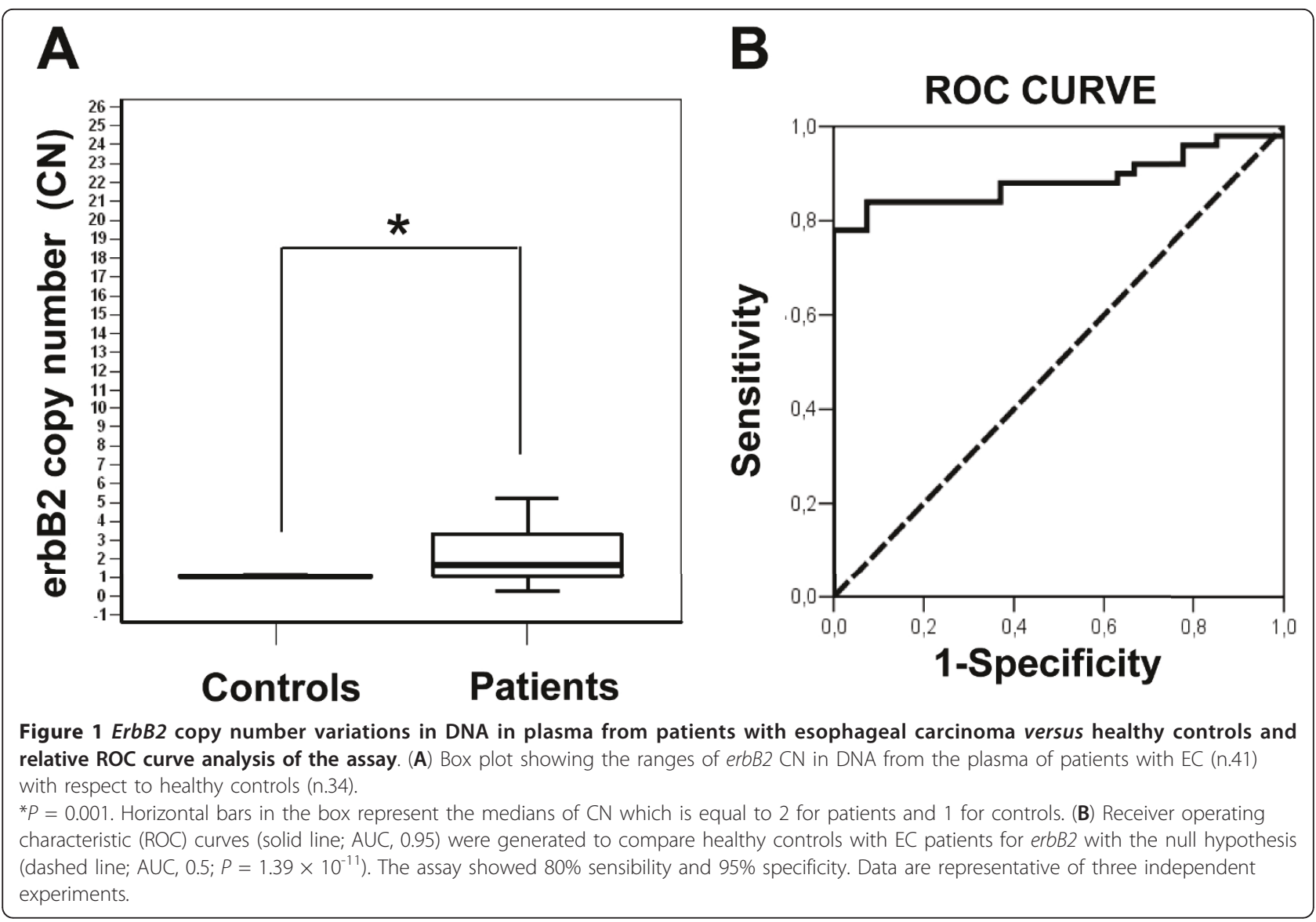

clinical features, except for tumor location when associated with erbB2 CN $>2(P=0.05)$. Despite the small number of patients, our dataset comprises all the characteristic of the tumor as regard $\mathrm{T}$ stage, $\mathrm{N}$ status, tumor grading, tumor location and histology, see Additional file 1: Supplemental table S1 (tab.S1). All CT values of real time PCR assay for EC patients and healthy controls subjects were showed in the Additional file 3: Supplemental table S2 (tab.S2).

\section{ErbB2 copy number variations predict survival rates in esophageal carcinoma patients}

We used Kaplan-Meier analyses to look for correlations between the erbB2 $\mathrm{CN}$ variations and $\mathrm{EC}$ patient progression-free survival. The survival curves for the EC patients were divided according to erbB2 $\mathrm{CN} \leq 2$ and erbB2 $\mathrm{CN}>2$, as illustrated in Figure 2 on the basis of $\mathrm{CN}$ median of EC patients. We also tried to divide the patients into lose $(\mathrm{CN}<1)$, normal $(2 \geq \mathrm{CN} \geq 1)$ and gain $(\mathrm{CN} \geq 2)$ of erbB2, 6, 14 and 21 patients respectively, and by using Kaplan-Meier analyses we did not reach a statistical significance but we saw the same tendency as for the survival analysis with cut-off 2 (Additional file 2: Supplemental Figure S1 C). The number of patients here analyzed is too small to be divided into three groups, for this reason we analyzed all the data with the CN cut-off value of 2. ErbB2 $\mathrm{CN}>2$ was significantly negatively correlated to the survival rates of these EC patients $(P=0.03$; Figure $2 \mathrm{~A})$.

In further analyses according to the tumor grading, the EC patients with a tumor grading $\mathrm{G} 2$ can be further stratified according to erbB2 $\mathrm{CN} \leq 2$ and erbB2 $\mathrm{CN}>2$, which were again significantly negatively correlated to the survival rates of these EC patients $(P=0.03$; Figure $2 B)$. These analyses for the EC patients with tumor gradings G1 and G3 did not show any statistically significant effects on their survival rates due to the small numbers of patients in these subgroups (data not shown).

Our dataset also showed an heterogeneous histological composition when stratified accordingly to the histotype. Here, erbB2 $\mathrm{CN}$ variations were significantly correlated to the survival rates of the adenocarcinoma cases $(P=$ 0.03; Figure $2 C$ ). Similarly, we analyzed the correlations between the $\mathrm{N}$ status and survival rates: erbB2 $\mathrm{CN}>2$ in the N1 subgroup was significantly negatively correlated to the survival rates of these EC patients $(P=0.05$, Figure 2D). Again, these analysis for the EC patients with 


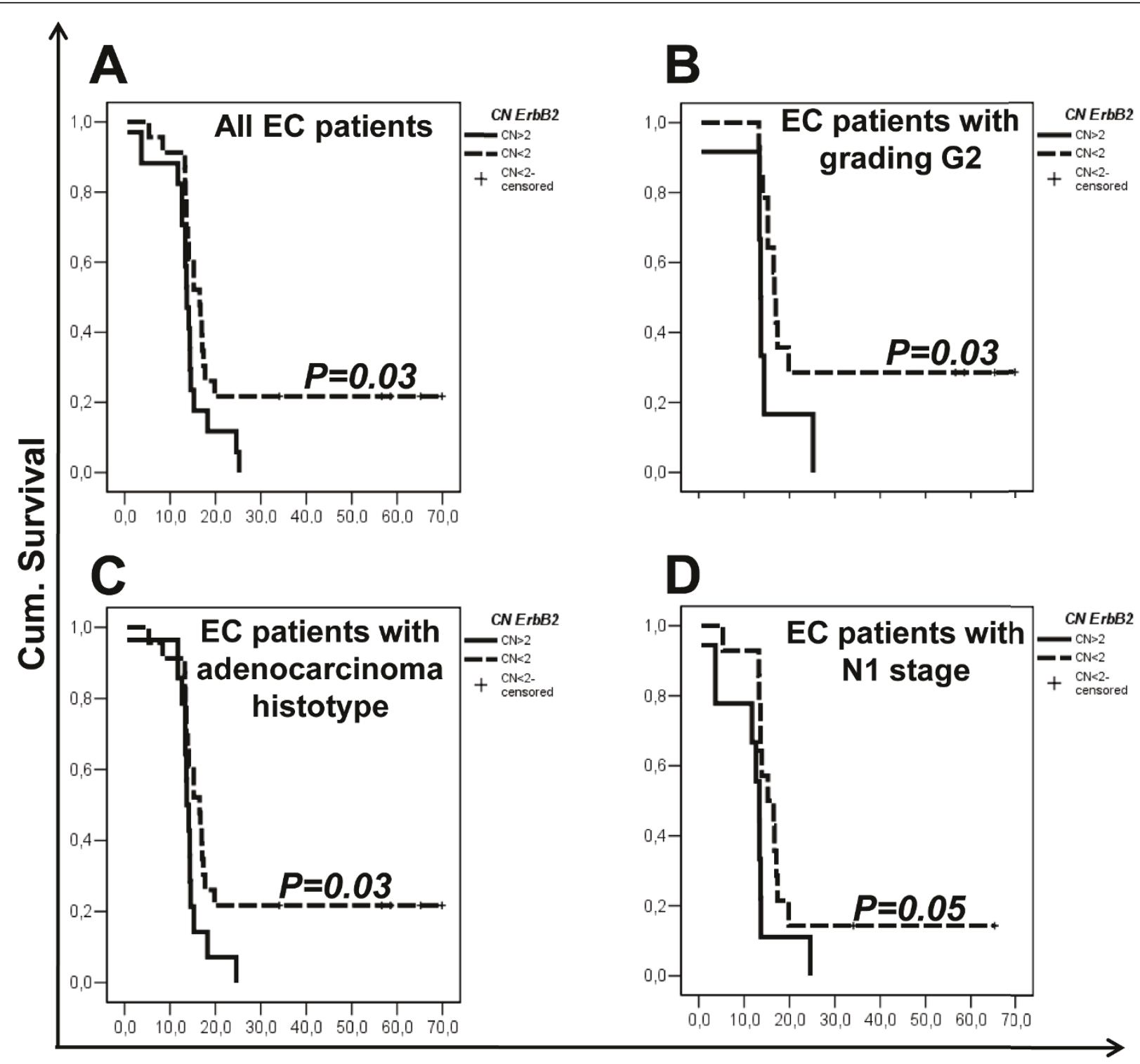

\section{Follow-up months}

Figure 2 Kaplan-Meier survival curves for erbB2 copy number variations in plasma from patients with esophageal carcinoma according to clinical characteristics. (A) All patients with EC; (B) EC patients with tumor grading G2; (C) EC patients with adenocarcinoma histology; (D) EC patients with N1 stage disease. The patients are divided according to erbB2 CN $\leq 2$ (solid line) and erbB2 CN $>2$ (dashed line) subgroups. Data are representative of three independent experiments.

an N status of N2 and N3 did not show any statistical significance for the survival rates due to the small numbers of patients in these subgroups (data not shown).

Correlations of erbB2 copy number variations with VEGF plasma levels

We then tested erbB2 $\mathrm{CN}$ for possible associations with VEGF protein levels in the plasma from the same EC patients (Figure 3). The VEGF levels data were available in our tissue/serum databank collection, and have been previously published [36]. The erbB2 $\mathrm{CN}$ variations did not show any significant direct associations with VEGF levels in the plasma (Figure 4A). However, when the EC patients were stratified into the low and high VEGF groups, as shown in Figure 4B, high VEGF levels in the plasma of those EC patients were significantly negatively correlated to their survival rates $(P<0.00001)$. In a further Kaplan-Meier analysis, we also looked at the influence of erbB2 $\mathrm{CN}$ variations in these $\mathrm{EC}$ patients with low and high VEGF levels: an erbB2 $\mathrm{CN}>2$ was 

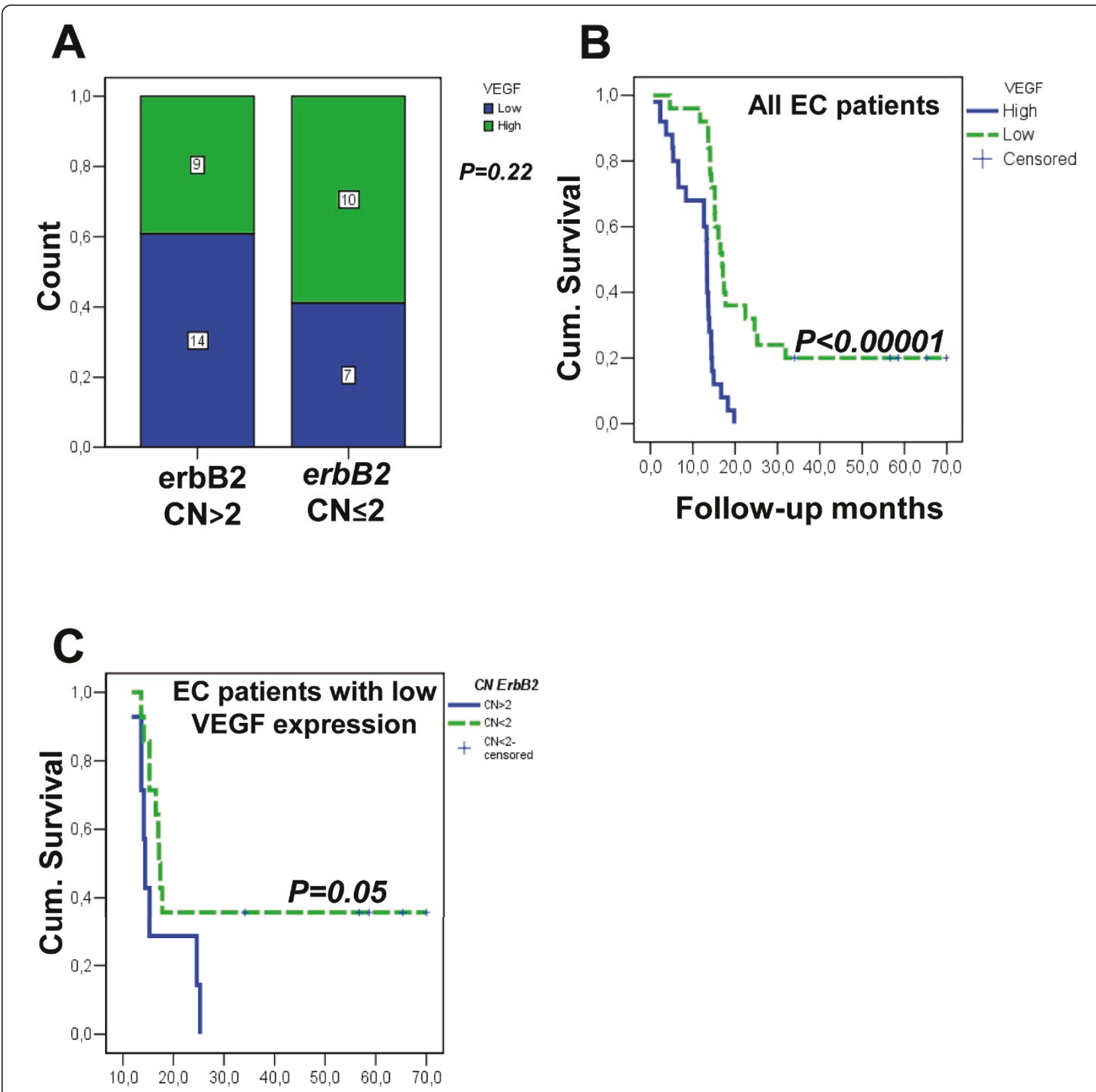

Follow-up months

Figure 3 ErbB2 copy number variations in plasma from patients with esophageal carcinoma according to VEGF plasma levels. (A) Histogram showing lack of significant correlation between erbB2 CN variations and VEGF plasma levels in all patients with EC ( $n$. 41), as indicated. The numbers in the bars show the EC patients in each sub-group. (B, C). Kaplan-Meier survival curves for all patients with EC according to low and high plasma levels of VEGF (B), and for patients with EC and low plasma levels of VEGF according to erbB2 CN $\leq 2$ (solid blu line) and erbB2 CN >2 (dashed green line). Data are representative of three independent experiments.

significantly negatively correlated to the survival rate of the EC patients with low VEGF expression $(P=0.05$; Figure $3 C$ ). Altogether, these results show that erbB2 $\mathrm{CN}>2$ status and low VEGF levels in the plasma of these EC patients appear to be useful to stratify a subgroup of patients with worse survival rates.
Isolation of circulating tumor cells from peripheral blood of esophageal carcinoma patients

To answer the question of whether this DNA in the plasma of these EC patients was derived from CTCs, we isolated these cells from these patients. Indeed, we detected CTCs that were disseminated in the peripheral 
blood in six of these patients with EC. The CTCs were isolated from the peripheral blood of these EC patients by sorting the cells negatively for CD45 (a specific antigen for lymphocytes) and by a gate based on epithelial cytoskeleton components: the cytokeratins CK8, CK18 and CK19, and CD326 (EpCAM) (see Methods). Both, the cytokeratins (CK8, CK18 and CK19) and the antigen
EpCAM have been used to identified epithelial cell adhesion molecules, as previously used by Stoecklein et al. as markers to isolate CTCs from lymph nodes and bone marrow of patients with EC [11]. As previously described, [37] we used the MDA-231T breast cell line as the positive control (Figure 4A). Here we show that we were only able to successfully isolated positive cells

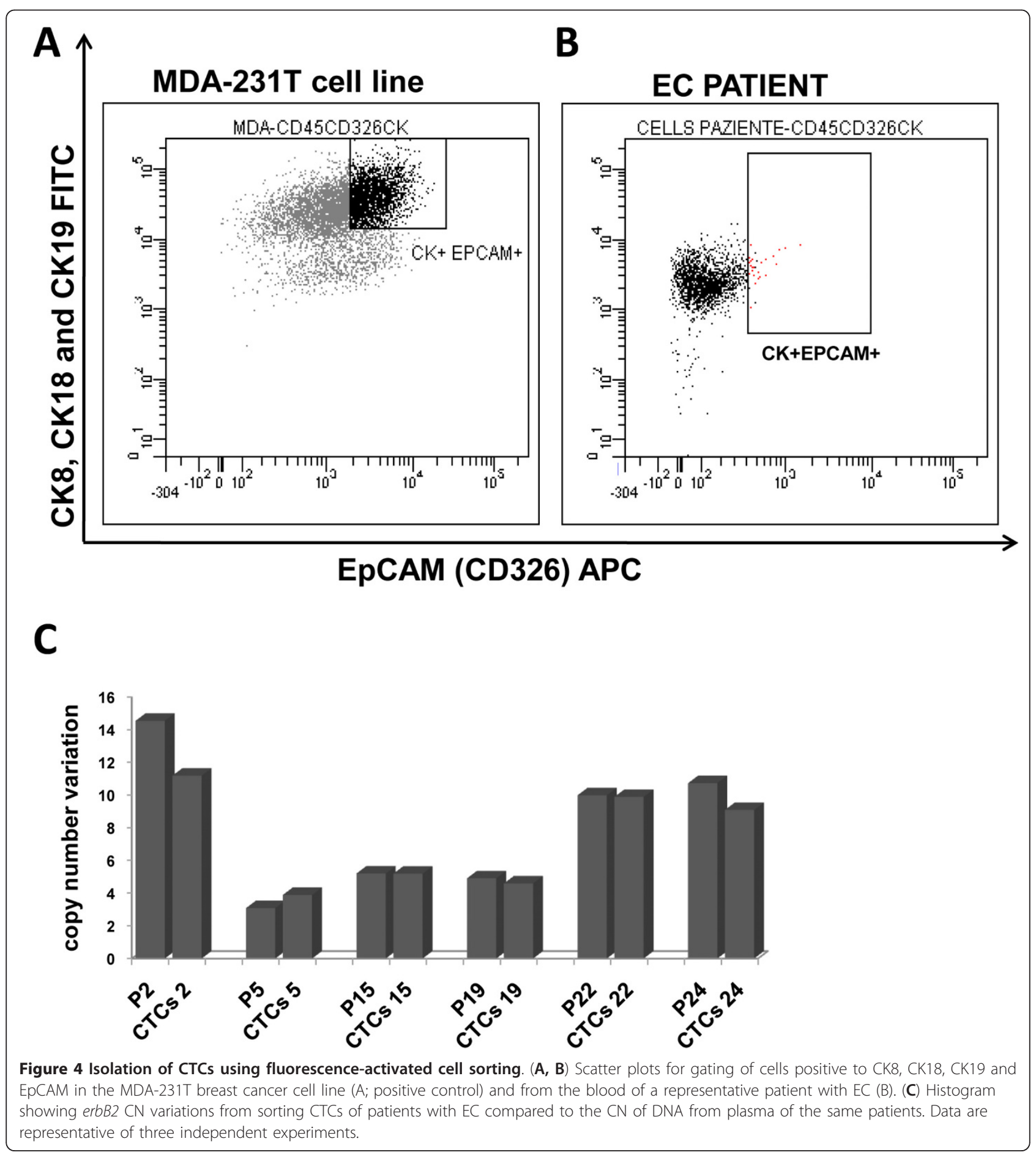


from the blood samples from the EC patients (about $0.05 \%-0.1 \%$ of the $2.0 \times 10^{6}$ cells analyzed; Figure $4 \mathrm{~B}$ ), from which we prepared genomic DNA for the determination of erbB2 CN. This analysis was performed in all of the other five samples analyzed, with similar results (data not shown). The peripheral blood of the healthy controls was analyzed in the same way, but did not show any cell population positive for CK8, CK18 and CK19 and EpCAM, and negative for CD45 (data not shown). The analyses of this DNA extracted from these CTCs of the EC patients showed that the erbB2 $\mathrm{CN}$ was in the same range $(\mathrm{CN}>2)$ as for the DNA isolated from the plasma of the same (six) EC patients (Figure 4C). The comparison between the $\mathrm{CN}$ values from plasma and from CTCs was showed in Additional file 4: Supplemental table S3 (tab.S3).

\section{ErbB2 protein expression in tumor tissue}

We additionally performed immunohistochemistry analysis for erbB2 protein staining (in parallel sections) in 13 esophageal primary tumor tissue samples, four of the tissues of which were included in the plasma DNA dataset previously analyzed. Some tissue staining examples are shown in the Additional file 5: Supplemental Figure S2. Strong expression of erbB2 was showed for the case code 1 patient (score +++ ), with intermediate expression of erbB2 for the case code 2 patient (score ++ ) and low expression for the case code 3 patient (score + ) (the Additional file 5: Supplemental Figure S2A). Control experiments showed weak staining of erbB2 in proliferative epithelial tissues of healthy esophageal mucosa (Additional file 5: Supplemental Figure S2 B).

\section{Discussion}

In clinical practice, the diagnosis and the staging of EC is mainly based on the use of morphological and functional clinical examinations. To date, serum-specific EC markers do not exist, which is in contrast with the situation for other tumors of the gastrointestinal tract. Examples here, can be seen for gastric cancer, where Ca.19.9 has important role in diagnosis. At this time, we can conclude that already identified single biomarkers show a lack of sufficient sensitivity and specificity in EC, and that it is likely that multiple markers will be needed simultaneously to address the diagnosis and prognosis of EC [3].

The relationship between erbB2 over-expression and responses to treatment has not yet been established for EC. New perspectives have been emerging, such as for instance from the TOGA trial, that showed efficacy results from a phase III study of trastuzumab (Hercep$\left.\operatorname{tin}^{\circledR}\right)$, a monoclonal antibody against erbB2: when given with chemotherapy, survival benefits were seen for patients with erbB2-positive early and metastatic gastric cancer [9]. Thus, the data in this TOGA trial showed that trastuzumab with chemotherapy is superior to chemotherapy alone, with median overall survival significantly improved with trastuzumab compared to chemotherapy alone: 13.5 versus 11.1 months, respectively. Trastuzumab is therefore a new and well-tolerated treatment for erbB2-positive gastrointestinal cancer [38].

VEGF is an additional marker, which is over-expressed in about $30 \%$ to $60 \%$ of esophageal tumors. High serum levels of VEGF correlate with advanced stages and poor overall survival in patients that receive curative surgery [39]. Several studies have shown that VEGF-C overexpression correlates with depth of tumor invasion, lymphatic invasion and lymph node metastasis.

CTCs and free DNA in plasma have been analyzed in many tumors, such as breast, colorectal, lung and renal carcinomas. These have been shown to be crucial links between primary cancers and those that reach a metastatic stage, which represent the leading cause of death for most malignancies [40-46]. Our study has evaluated the evolving model of detection of tumor marker $\mathrm{CN}$ in DNA from plasma of EC patients. We have here identified erbB2 CN variations in the cell-free DNA of 41 patients with EC in comparison with 34 healthy controls. Our results are in agreement with the study of Chiang PW. et al., that showed erbB2 amplification in 39 plasma from esophageal carcinoma patients with only adenocarcinoma histotype. The system of detection of erbB2 in DNA from plasma by real-time PCR is innovative and with the validation in a larger cohort of patients can be used for monitoring the assessment of the extent of tumor dissemination and the potential development of distant metastasis. This method uses an easier and not invasive peripheral blood sample in respect with the FISH assay (PathVysion FISH assay) performed on tumor biopsies actually approved by the US Food and Drug Administration (FDA) for determining the eligibility for Herceptin clinical treatment in breast carcinoma with erbB2 amplification.

We have further analyzed the erbB2 CN from CTCs isolated from patients with $\mathrm{EC}$ and we have demonstrate that it is similar to the DNA isolated from the plasma of the same patients. These data indicate that in the healthy controls, the DNA that we extracted was derived from blood cells (mainly lymphocytes and granulocytes); instead, in the EC patients, the free DNA in the plasma is mainly derived from CTCs (see Additional file 6: Supplemental Table S4, for estimation of the DNA content in plasma). At this time, a question remains over the origin of these CTCs: Are those cells derived from primary tumors or from cells that will create a metastases foci? We cannot at present exclude that this DNA derived from the primary tumor cells because of our lack of DNA from the primary tumors in this study. 
However, our data related to the erbB2 $\mathrm{CN}$, shown for this cohort analysis, is in agreement with another study that has shown erbB2 amplification in CTCs isolated from lymph nodes and bone marrow in $50 \%$ of EC patients [11]. This study demonstrated that the rate of erbB2 amplification is higher in CTCs than in the primary tumors, where the rates of amplification were estimated at about $10 \%[10,47]$. These data are in agreement with the observation that erbB2 $\mathrm{CN}$ variations are a later phenomenon in EC that is mainly associated with the circulating tumor cells. Our data additionally demonstrate that the CTCs isolated from the peripheral blood of these EC patients have a similar type of erbB2 amplification to that seen by Stoecklein et al. in CTCs isolated from bone marrow and lymph nodes [11]. The present study underlines that the detection of cell-free DNA from plasma through the taking of a non-invasive blood sample can provide relevant information on the disease status of patients with EC. It is important to underline that despite the small number of EC patients (n.41) included in our cohort, the incidence of this tumor is of 2195 cases for year in Italy with 40 cases in Naples and a raw rate (number of cases per one hundred thousand of inhabitants for year) of 2 in southern Italy (data from Italian Association tumors register AIRTUM 2000-2003; see: http://www.registri-tumori.it/ $\mathrm{cms} /$ ). Furthermore, our dataset is heterogeneous for composition resembling all the clinical characteristics of the esophageal carcinoma.

We have shown here a correlation between erbB2 $\mathrm{CN}$ from plasma and progression-free survival in patients with EC with 70 months (5,8 years) of follow-up. The EC patients were divided into two subgroup on the basis of $\mathrm{CN}$ median (cut-off $\mathrm{CN}=2$ ), other separation in subgroups were made but they did not shown correlation to progression-free survival for the small number of patients here analyzed (see the Additional file 2: Supplemental Figure $\mathrm{S} 1 \mathrm{C}$ ). The EC patients with erbB2 $\mathrm{CN}$ $\leq 2$ showed a better survival with respect to those with $\mathrm{CN}>2$ erbB2. These data demonstrate that the detection of erbB2 $\mathrm{CN}$ in the plasma of EC patients can predict the survival rates of patients before the use of clinical resection strategies. These data emphasize the results obtained by Mimura et al., that found an association only between the survival rate and the erbB2 gene amplification ( 7 positive patients versus 59 negative patients) detected by fluorescence in situ hybridization (FISH) method and not between the survival rate and positive or negative erbB2 staining detected by immunohistochemistry assay [46]. Furthermore, Kuwabara et al., also demonstrated the correspondence between gene amplification (analyzed by FISH) and protein expression (analyzed by immunohistochemistry) of erbB2, underlining that gene amplification is an indicator of poor prognosis in esophageal carcinoma [35].

In particular, we found that an $\operatorname{erbB} 2 \mathrm{CN}>2$ was correlated to a worst survival rate in the adenocarcinoma histotype. Of note, esophageal adenocarcinoma has been shown to have increased in western countries over the last half century, and especially in European Caucasian white men, although esophageal squamous cell carcinoma remains the dominant type of EC in both western and Asian countries [47-49]. The rapid increase of this adenocarcinoma histotype has been attributed to an increased prevalence of gastroesophageal reflux disease and obesity [48-50].

Furthermore, our dataset confirms the importance of $\mathrm{N}$ status evaluation through our Kaplan-Meier analysis. When divided according to $\mathrm{N}$ status, an erbB2 $\mathrm{CN}>2$ impaired survival rates of patients with an N1 status, confirming the importance of the amplification of the erbB2 gene in the prediction of a worse clinical outcome.

We also confirmed the importance of the VEGF expression in our dataset, demonstrating that high VEGF expression impairs the survival rate of these EC patients. Moreover, we have identified a new EC category risk: low VEGF expression and erbB2 $\mathrm{CN}>2$. These data are of importance because of the potential new therapies, anti-erbB2, that might be applied to EC patients who will not derive any benefit from anti-VEGF treatment.

\section{Conclusion}

The use of these methods to detect DNA in the plasma of such EC patients should greatly benefit the "early detection" phase before tumor resection and chemotherapy, and should enhance the importance for changes in therapies for those low VEGF-positive EC patients. The validation of the erbB2 detection in a large scale population thus represents a new prognostic marker that can be used as a sign of EC early warning, and for the prediction of the disease progression. Thus, inhibition of erbB2 activity might represent a new avenue for successful inhibition of potential metastasis formation, and represents a new therapeutic target for future personalized cancer therapies.

These data indicate the association between erbB2 $\mathrm{CN}$ variations and progression-free survival in these patients with EC. As previously said, the number of patients analyzed here is not sufficient to draw a conclusion on the possible diagnostic application, although we know that our tumors dataset represents a well morphological distribution in the Caucasian population affected by esophageal cancer. At this time, a large study that can be designed to include both EC and other tumors of the 
gastrointestinal tract, thus will definitively enhancing our methodology and findings.

\section{Additional material}

Additional file 1: Supplemental Table S1: Association of erbB2 copy number variations with the clinicopathological features of the patients with esophageal carcinoma.

Additional file 2: Supplemental Figure S1: Calibration curve for erbB2 and $\beta$-actin genes relating cycle threshold to gene copy number. (A) For the erbB2 gene $\mathrm{CN}$. Top right, equation of the curve and the relative mean correlation coefficient (R2). (B) For the $\beta$-actin gene $\mathrm{CN}$. Top right, as for (A). (C) Kaplan-Meier survival curves for all patients with EC according to lose, normal and gain erbB2 $\mathrm{CN}$.

Additional file 3: Supplemental Table S2: CT values of real time PCR of erbB2 and $\beta$-actin genes for all patients and controls.

Additional File 4: Supplemental Table S3: Copy number variation of CTCs from EC patients compared to copy number variation of DNA from plasma of the same patients.

Additional File 5: Supplemental Figure S2: ErbB2 in esophageal tumor tissues. (A) Patterns of ErbB2 staining with a polyclonal antibody in EC tumor tissues 1, 2 and 3, showing scores of,+++++ and + , respectively. (B) ErbB2 staining as for (A), in healthy esophageal mucosa (CTR).

Additional File 6: Supplemental Table S4: Quantization of DNA extracted from plasma of patients and controls.

\section{Abbreviations}

EC: esophageal carcinoma; CN: copy number variations; CTCs: circulating tumor cells.

\section{Acknowledgements}

The authors would like to thank: University Federico II, School of Medicine, for sharing the healthy control blood samples, the CEINGE Service Platforms Facilities, Scuola di Specializzazione in Genetica Medica, Università Federico II, (Naples, Italy). For the critical scientific and technical aspects within CTCS in flow cytometry, Prof. Luigi Del Vecchio.

This study was financed by: FP7-Tumic HEALTH-F2-2008-201662 (MZ) and Associazione Italiana per la Ricerca sul Cancro (AIRC, 2009-2011) (MZ).

\section{Author details}

'CEINGE, Centro di Ingegneria Genetica e Biotecnologia Avanzate, Via Gaetano Salvatore 486, 80145, Naples, Italy. ${ }^{2}$ Dipartimento di Biochimica e Biotecnologie Mediche, Università degli Studi di Napoli "Federico II", Naples, Italy. ${ }^{3}$ Dipartimento Medico-Chirurgico di Internistica Clinica e Sperimentale "F. Magrassi e A. Lanzara" SUN, Seconda Università degli Studi, Naples, Italy.

\section{Authors' contributions}

IA conducted and designed most of the experiments and participate to the manuscript writing and editing; GP performed the cloning for the real time experiments; LV performed samples collection; PDA performed real time setup experiments; $\mathrm{MO}$ coordinate samples collection and clinical database construction, MC performed statistical analysis; DM performed the immunohistochemistry analyses; MG performed FACS analyses; GT performed the pathological scoring; FC and FDV contributed to the collection of blood samples, clinical follow-up and preparation of the manuscript; MZ design and coordinate the study, then contribute to the final critical review and editing of the manuscript.

All authors read and approved the final manuscript.

\section{Competing interests}

The authors declare that they have no competing interests.

Received: 28 September 2010 Accepted: 11 April 2011 Published: 11 April 2011
References

1. Ferlay J, Autier P, Boniol M, Heanue M, Colombet M, Boyle P: Estimates of the cancer incidence and mortality in Europe in 2006. Ann Oncol 2007, 18(3):581-592.

2. Lagergren J: Adenocarcinoma of oesophagus: what exactly is the size of the problem and who is at risk? Gut 2005, 54(Suppl 1):i1-5.

3. Bird-Lieberman EL, Fitzgerald RC: Early diagnosis of oesophageal cancer. Br J Cancer 2009, 101(1):1-6.

4. Endo M, Kawano T: Detection and classification of early squamous cell esophageal cancer. Dis Esophagus 1997, 10(3):155-158.

5. Ancona E, Rampado S, Cassaro M, Battaglia G, Ruol A, Castoro C, Portale G, Cavallin F, Rugge M: Prediction of lymph node status in superficial esophageal carcinoma. Ann Surg Oncol 2008, 15(11):3278-3288.

6. Koppert LB, Wijnhoven BP, van Dekken H, Tilanus HW, Dinjens WN: The molecular biology of esophageal adenocarcinoma. J Surg Oncol 2005, 92(3):169-190.

7. Crew KD, Neugut Al: Epidemiology of upper gastrointestinal malignancies. Semin Oncol 2004, 31(4):450-464.

8. Vallbohmer D, Lenz HJ: Predictive and prognostic molecular markers in outcome of esophageal cancer. Dis Esophagus 2006, 19(6):425-432.

9. Slamon DJ, Leyland-Jones B, Shak S, Fuchs H, Paton V, Bajamonde A, Fleming T, Eiermann W, Wolter J, Pegram M, et al: Use of chemotherapy plus a monoclonal antibody against HER2 for metastatic breast cancer that overexpresses HER2. N Engl J Med 2001, 344(11):783-792.

10. Reichelt U, Duesedau P, Tsourlakis M, Quaas A, Link BC, Schurr PG, Kaifi JT, Gros SJ, Yekebas EF, Marx A, et al: Frequent homogeneous HER-2 amplification in primary and metastatic adenocarcinoma of the esophagus. Mod Pathol 2007, 20(1):120-129.

11. Stoecklein NH, Hosch SB, Bezler M, Stern F, Hartmann CH, Vay C, Siegmund A, Scheunemann P, Schurr P, Knoefel WT, et al: Direct genetic analysis of single disseminated cancer cells for prediction of outcome and therapy selection in esophageal cancer. Cancer Cell 2008, 13(5):441-453.

12. Chiang PW, Beer DG, Wei WL, Orringer MB, Kurnit DM: Detection of erbB-2 amplifications in tumors and sera from esophageal carcinoma patients. Clin Cancer Res 1999, 5(6):1381-1386.

13. Folkman J: Angiogenesis in cancer, vascular, rheumatoid and other disease. Nat Med 1995, 1(1):27-31.

14. Risau W: Mechanisms of angiogenesis. Nature 1997, 386(6626):671-674

15. He Y, Karpanen T, Alitalo K: Role of lymphangiogenic factors in tumor metastasis. Biochim Biophys Acta 2004, 1654(1):3-12.

16. Ferrara N: VEGF and the quest for tumour angiogenesis factors. Nat Rev Cancer 2002, 2(10):795-803.

17. Mustonen T, Alitalo K: Endothelial receptor tyrosine kinases involved in angiogenesis. J Cell Biol 1995, 129(4):895-898.

18. Kitadai Y, Amioka T, Haruma K, Tanaka S, Yoshihara M, Sumii K, Matsutani N, Yasui W, Chayama K: Clinicopathological significance of vascular endothelial growth factor (VEGF)-C in human esophageal squamous cell carcinomas. Int J Cancer 2001, 93(5):662-666.

19. von Rahden BH, Stein HJ, Puhringer F, Koch I, Langer R, Piontek G, Siewert JR, Hofler H, Sarbia M: Coexpression of cyclooxygenases (COX-1, COX-2) and vascular endothelial growth factors (VEGF-A, VEGF-C) in esophageal adenocarcinoma. Cancer Res 2005, 65(12):5038-5044.

20. Krzystek-Korpacka M, Matusiewicz M, Diakowska D, Grabowski K, Blachut K, Banas T: Up-regulation of VEGF-C secreted by cancer cells and not VEGFA correlates with clinical evaluation of lymph node metastasis in esophageal squamous cell carcinoma (ESCC). Cancer Lett 2007, 249(2):171-177.

21. Pathak AK, Bhutani M, Kumar S, Mohan A, Guleria R: Circulating cell-free DNA in plasma/serum of lung cancer patients as a potential screening and prognostic tool. Clin Chem 2006, 52(10):1833-1842.

22. Hoon DS, Spugnardi M, Kuo C, Huang SK, Morton DL, Taback B: Profiling epigenetic inactivation of tumor suppressor genes in tumors and plasma from cutaneous melanoma patients. Oncogene 2004, 23(22):4014-4022.

23. Koyanagi K, Mori T, O'Day SJ, Martinez SR, Wang HJ, Hoon DS: Association of circulating tumor cells with serum tumor-related methylated DNA in peripheral blood of melanoma patients. Cancer Res 2006, 66(12):6111-6117.

24. Andolfatto S, Namour F, Garnier AL, Chabot F, Gueant JL, Aimone-Gastin I: Genomic DNA extraction from small amounts of serum to be used for alpha1-antitrypsin genotype analysis. Eur Respir J 2003, 21(2):215-219. 
25. Taback B, Fujiwara Y, Wang HJ, Foshag LJ, Morton DL, Hoon DS: Prognostic significance of circulating microsatellite markers in the plasma of melanoma patients. Cancer Res 2001, 61(15):5723-5726.

26. Koike M, Hibi K, Kasai Y, Ito K, Akiyama S, Nakao A: Molecular detection of circulating esophageal squamous cell cancer cells in the peripheral blood. Clin Cancer Res 2002, 8(9):2879-2882.

27. Castaldo G, Tomaiuolo R, Sanduzzi A, Bocchino ML, Ponticiello A, Barra E, Vitale D, Bariffi F, Sacchetti L, Salvatore F: Lung cancer metastatic cells detected in blood by reverse transcriptase-polymerase chain reaction and dot-blot analysis. J Clin Oncol 1997, 15(11):3388-3393.

28. Klein CA, Stoecklein NH: Lessons from an aggressive cancer: evolutionary dynamics in esophageal carcinoma. Cancer Res 2009, 69(13):5285-5288.

29. Nicholson Rl, Gee JM, Harper ME: EGFR and cancer prognosis. Eur J Cancer 2001, 37(Suppl 4):S9-15.

30. Livak KJ, Schmittgen TD: Analysis of relative gene expression data using real-time quantitative PCR and the 2(-Delta Delta C(T)) Method. Methods 2001, 25(4):402-408.

31. Ponchel F, Toomes C, Bransfield K, Leong FT, Douglas SH, Field SL, Bell SM, Combaret V, Puisieux A, Mighell AJ, et al: Real-time PCR based on SYBRGreen I fluorescence: an alternative to the TaqMan assay for a relative quantification of gene rearrangements, gene amplifications and micro gene deletions. BMC Biotechnol 2003, 3:18.

32. Yuan JS, Reed A, Chen F, Stewart CN Jr: Statistical analysis of real-time PCR data. BMC Bioinformatics 2006, 7:85.

33. Dhanasekaran S, Doherty TM, Kenneth J: Comparison of different standards for real-time PCR-based absolute quantification. J Immunol Methods 354(1-2):34-39.

34. Godornes C, Leader BT, Molini BJ, Centurion-Lara A, Lukehart SA: Quantitation of rabbit cytokine mRNA by real-time RT-PCR. Cytokine 2007, 38(1):1-7.

35. Sato-Kuwabara $Y$, Neves Jl, Fregnani JH, Sallum RA, Soares FA: Evaluation of gene amplification and protein expression of HER-2/neu in esophageal squamous cell carcinoma using Fluorescence in situ Hybridization (FISH) and immunohistochemistry. BMC Cancer 2009, 9:6.

36. Lieto E, Ferraraccio F, Orditura M, Castellano P, Mura AL, Pinto M, Zamboli A, De Vita F, Galizia G: Expression of vascular endothelial growth factor (VEGF) and epidermal growth factor receptor (EGFR) is an independent prognostic indicator of worse outcome in gastric cancer patients. Ann Surg Oncol 2008, 15(1):69-79.

37. Kallergi G, Markomanolaki H, Giannoukaraki V, Papadaki MA, Strati A, Lianidou ES, Georgoulias V, Mavroudis D, Agelaki S: Hypoxia-inducible factor1 alpha and vascular endothelial growth factor expression in circulating tumor cells of breast cancer patients. Breast Cancer Res 2009, 11(6):R84

38. Bang Yung-Jue, Eric Van Cutsem, Feyereislova Andrea, Hyun C Chung, Shen Lin, Sawaki Akira, Lordick Florian, for the ToGA Trial Investigators, et al: Trastuzumab in combination with chemotherapy versus chemotherapy alone for treatment of HER2-positive advanced gastric or gastrooesophageal junction cancer (ToGA): a phase 3, open-label, randomised controlled trial. Lancet 2010, 376:687-97.

39. Shih CH, Ozawa S, Ando N, Ueda M, Kitajima M: Vascular endothelial growth factor expression predicts outcome and lymph node metastasis in squamous cell carcinoma of the esophagus. Clin Cancer Res 2000, 6(3):1161-1168.

40. Banki F, Yacoub WN, Hagen JA, Mason RJ, Ayazi S, DeMeester SR, Lipham JC, Danenberg K, Danenberg P, DeMeester TR: Plasma DNA is more reliable than carcinoembryonic antigen for diagnosis of recurrent esophageal cancer. J Am Coll Surg 2008, 207(1):30-35.

41. Van der Auwera I, Elst HJ, Van Laere SJ, Maes H, Huget P, van Dam P, Van Marck EA, Vermeulen PB, Dirix LY: The presence of circulating total DNA and methylated genes is associated with circulating tumour cells in blood from breast cancer patients. Br J Cancer 2009, 100(8):1277-1286.

42. Boni L, Cassinotti E, Canziani M, Dionigi G, Rovera F, Dionigi R: Free circulating DNA as possible tumour marker in colorectal cancer. Surg Oncol 2007, 16(Suppl 1):S29-31.

43. Diehl F, Schmidt K, Durkee KH, Moore KJ, Goodman SN, Shuber AP, Kinzler KW, Vogelstein B: Analysis of mutations in DNA isolated from plasma and stool of colorectal cancer patients. Gastroenterology 2008, 135(2):489-498.

44. Tomita H, Ichikawa D, Ikoma D, Sai S, Tani N, Ikoma H, Fujiwara H, Kikuchi S, Okamoto K, Ochiai T, et al: Quantification of circulating plasma DNA fragments as tumor markers in patients with esophageal cancer. Anticancer Res 2007, 27(4C):2737-2741.

45. Maheswaran S, Sequist LV, Nagrath S, Ulkus L, Brannigan B, Collura CV, Inserra E, Diederichs S, lafrate AJ, Bell DW, et al: Detection of mutations in EGFR in circulating lung-cancer cells. N Engl J Med 2008, 359(4):366-377.

46. Perego RA, Corizzato M, Brambilla P, Ferrero S, Bianchi C, Fasoli E, Signorini S, Torsello B, Invernizzi L, Bombelli S, et al: Concentration and microsatellite status of plasma DNA for monitoring patients with renal carcinoma. Eur J Cancer 2008, 44(7):1039-1047.

47. Mimura K, Kono K, Hanawa M, Mitsui F, Sugai H, Miyagawa N, Ooi A, Fujii H: Frequencies of HER-2/neu expression and gene amplification in patients with oesophageal squamous cell carcinoma. Br J Cancer 2005, 92(7):1253-1260.

48. Bresalier RS: Barrett's Esophagus and esophageal adenocarcinoma. Annu Rev Med 2009, 60:221-231.

49. Reid BJ, Li X, Galipeau PC, Vaughan TL: Barrett's oesophagus and oesophageal adenocarcinoma: time for a new synthesis. Nat Rev Cancer 10(2):87-101.

50. Hongo M, Nagasaki Y, Shoji T: Epidemiology of esophageal cancer: Orient to Occident. Effects of chronology, geography and ethnicity. J Gastroenterol Hepatol 2009, 24(5):729-735.

\section{Pre-publication history}

The pre-publication history for this paper can be accessed here:

http://www.biomedcentral.com/1471-2407/11/126/prepub

doi:10.1186/1471-2407-11-126

Cite this article as: Andolfo et al:: Detection of erbB2 copy number

variations in plasma of patients with esophageal carcinoma. BMC Cancer 2011 11:126.

\section{Submit your next manuscript to BioMed Central and take full advantage of:}

- Convenient online submission

- Thorough peer review

- No space constraints or color figure charges

- Immediate publication on acceptance

- Inclusion in PubMed, CAS, Scopus and Google Scholar

- Research which is freely available for redistribution 